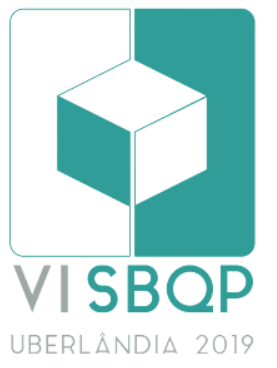

\title{
A PROLIFERAÇÃO DOS HÍBRIDOS: DA CIDADE AO EDIFÍCIO - UMA ANÁLISE CRÍTICA E PROPOSITIVA
}

\author{
KRAVCHENKO, Larissa \\ Pontifícia Universidade Católica de Goiás, e-mail: larissakrav@outlook.com \\ PEREIRA, Pedro Henrique Máximo \\ Pontifícia Universidade Católica de Goiás, Universidade Estadual de Goiás, e-mail: \\ arqurb.phmp@gmail.com
}

\begin{abstract}
RESUMO
Neste artigo discute-se os resultados teóricos e projetuais de um Trabalho de Conclusão de Curso em Arquitetura e Urbanismo, desenvolvido na Escola de Artes e Arquitetura da PUC-Goiás. Trata-se de um complexo de edifícios híbridos pensados e projetados para o Setor Central da cidade de Goiânia, capital de Goiás. A discussão centra-se na falência dos edifícios multifuncionais, em larga medida adotados como soluções para os problemas metropolitanos e aponta para a emergência dos edifícios híbridos na tentativa de resolvê-los. Assim, neste texto encontra-se parte da discussão teórica e as soluções urbano-arquitetônicas adotadas.
\end{abstract}

Palavras-chave: Híbrido, Centro, Intervenção, Requalificação Urbana.

\begin{abstract}
This paper discusses the theoretical and conceptual results of a Course Completion Work in Architecture and Urbanism, developed at the School of Arts and Architecture of PUC-Goiás. It is a complex of hybrid spaces designed and designed for the Central Sector of the city of Goiânia, capital of Goiás. The focus is on the bankruptcy of multifunctional buildings, largely adopted as solutions to metropolitan problems and points to an emergency of hybrid projects in an attempt to solve them. Thus, a text is part of the discussion and as urban-architectural solutions adopted.
\end{abstract}

Keywords: Hybrid, Downtown, Intervention, Urban Requalification.

\section{INTRODUÇÃO - OS HÍBRIDOS}

Este texto refere-se a um relato de experiências, de produção e orientação, de um Trabalho de Conclusão de Curso desenvolvido na Escola de Artes e Arquitetura da PUC-Goiás. Trata-se de uma aposta ou um teste, cujo eixo estruturador acena na direção de um paradigma teórico: os híbridos. Neste sentido, uma série de procedimentos de trabalho foram adotados e formulouse uma proposta urbano-arquitetônica para o Setor Central de Goiânia que sintetizasse, provocasse e difundisse os híbridos.

O híbrido enquanto paradigma teórico e do real está no lócus da produção arquitetônica contemporânea, seja entendendo o próprio edifício projetado como um produto híbrido, seja entendendo-o como difusor de encontros, choques, experiências e contaminações. Refere-se, a priori, de um entendimento maior da cidade como um híbrido de tempos, de usuários, de usos, de localidades e globalidades, de realidades e virtualidades. Enfim, o híbrido como um paradigma encara a impureza, a contaminação, a mistura,

KRAVCHENKO, L.; PEREIRA, P. H. M. A proliferação dos híbridos: da cidade ao edifício - uma análise crítica e propositiva. In: SIMPÓSIO BRASILEIRO DE QUALIDADE DO PROJETO NO AMBIENTE CONSTRUÍDO, 6., 2019, Uberlândia. Anais... Uberlândia: PPGAU/FAUeD/UFU, 2019. p. 1450-1461. DOI https://doi.org/10.14393/sbqp19130. 
a montagem e a colagem como práticas motrizes da nossa era, em busca da alteridade, da tolerância ativa, da diversidade e da abertura relacional.

Neste sentido, apresentamos o trabalho desenvolvido em duas etapas. A primeira discute os híbridos em proliferação, entendendo-o como um paradigma histórico da humanidade, mas também da própria cidade e da arquitetura. Assim, em A proliferação dos híbridos - da cidade ao edifício, busca-se realizar uma síntese do pensamento arquitetônico e urbanístico mediante o paradigma dos híbridos. Num segundo momento, por título Uma análise crítica e propositiva para o centro de Goiânia, coloca-se à prova as formulações teóricas pensadas e processualmente estabelecidas, revelando a proposta de projeto submetida e avaliada.

\section{A PROLIFERAÇÃO DOS HÍBRIDOS - DA CIDADE AO EDIFÍ́CIO}

"A pureza é um mito", apontou-nos recentemente Paola Berenstein Jacques (2018) em sua tese de titulação. Nela, a autora percorreu a tradição modernista, de origem impura, imprecisa e inacabada e mostrou-nos que sua produção - ou parte considerável - foi, por excelência, híbrida. Essas críticas e constatações não são novas e já foram anunciadas repetidas vezes por autores como Kenneth Frampton, William Curtis, Josep Maria Montaner ou mais recentemente por Jean-Louis Cohen, portanto, Berenstein Jacques não é a primeira pessoa a identificar essas dissonâncias entre o discurso e a prática no Movimento Moderno (MM). Conscientes disso, iniciamos este texto nos referindo a este trabalho, pois ele demarca exatamente o horizonte de cem anos da clássica publicação Après le Cubisme, de Le Corbusier e Amédée Ozenfant. Cem anos e dois opostos: por um lado, Corbusier e Ozenfant, em um manifesto, proclamam e enaltecem o purismo; e Paola Berenstein, em uma tese-manifesto de mesmo tom, anuncia a falência de tal discurso, por outro.

Neste ínterim de cem anos muitos fatos ocorreram e muitos fenômenos foram postos à prova. Enquanto a proliferação dos puros parecia hegemônica durante a Segunda Guerra (1939-1945) - e pressupunha a destruição imperativa dos híbridos -, a proliferação dos híbridos, em resistência, acunhava-se pelos sótãos, telhados, porões, lareiras, matas ou mesmo rastejante em plantações de girassóis. Enquanto a proliferação dos puros iludia-se num discurso de autonomia do objeto (por acreditar cegamente na autonomia do sujeito), os híbridos corroíam, em silêncio, tal autonomia. Enquanto os arquitetos puristas propuseram articulações sistêmicas de suas partes componentes - como o funcionalismo, a unicidade, a abstração (a fim de manter e proteger sua totalidade discursiva) -, os híbridos reforçavam as relações com outros ausentes, deslocavam-se pela historicidade dos fatos, afastavam a objetualidade de suas práticas e insistiam em sua processualidade. Enfim, a proliferação dos híbridos alastrou-se em sobremaneira pelos horizontes da história e ainda insiste em eclodir e demarcar seu espaço.

\subsection{Os híbridos e a crise do MM}

No período de formulação do $M M$, o discurso da autonomia do objeto do sistema Beaux-arts se manteria em figuras como Le Corbusier, Mies van der Rohe, Walter Gropius, Eero Saarinen e Ludwig Hilberseimer. Tal compreensão se deu de dois modos, a princípio. Le Corbusier, Gropius e Hilberseimer a partir de 
propostas funcionalistas e Saarinen e Rohe a partir de obras isoladas. Em maior ou menor grau, tal discurso e ambas posturas também tenderiam a se unificar, de modo irrestrito, na proposta de integração das artes. Nele, o objeto arquitetônico seria o ponto de convergência para o qual se endereçariam, em específico, a pintura e a escultura. Na América Latina, especialmente no Brasil e México, tal discurso soou forte, com produções de representatividade internacional como a Igreja São Francisco de Assis (1943), em Belo Horizonte, de Oscar Niemeyer com painéis de Cândido Portinari e a casa Luis Barragán (1948), na Cidade do México que, em consonância com a cultura popular (ênfase nos muralistas), estipulou planos-murais de cores fortes, contrastantes e texturizadas. Brasília (1957-1960), a cidade apoteótica do MM projetada por Lúcio Costa, foi também o ponto de convergência da integração das artes e, apesar de guardar certa unidade urbano-arquitetônica, nasce híbrida em função da atuação de Athos Bulcão, Burle Marx, Portinari, Niemeyer, Lucio Costa entre outros.

Neste sentido, a postura híbrida no MM parecia basilar, não fosse a eclosão do The International Style (1932) que deu ênfase ao discurso purista em escala global. O encobrimento das diferenças, dissonâncias e desvios por parte desse discurso foi a causa de seu enfraquecimento durante a crise do racionalismo ocidental do pós-Guerra. Cabe aqui a ressalva de que o termo crise não indica um abalo, mas disputa e julgamento. Neste sentido, a chamada crise do MM delimita uma disputa de narrativas, um excesso de desdobramentos cuja análise e juízo precediam qualquer avanço de tais práticas. Assim, a depressão da hegemonia do racionalismo incitaria uma mudança de postura. O caso da virada de curso na trajetória de Le Corbusier sinaliza esse redirecionamento, iniciando com Unité d'Habitation (1952), passando pela capela de La Ronchamp (1955) o convento de La Tourette (1960), e o icônico projeto urbano para Chandgarh (1951).

\subsubsection{As respostas à crise do $M M$}

As respostas ao esfacelamento da autonomia do objeto foram imediatas. $O$ decurso dessa história se desdobrou em posições relacionais, não deterministas e não impositivas. Referente ao primeiro momento, conhecido na historiografia como o período de revisão do $M M$, o encaminhamento dos objetos autônomos direciona-se aos sistemas abertos, seja das partes integrantes do todo projetado, da relação do novo com a cidade preexistente, ou mesmo do novo com o território e a paisagem. A mudança de postura na direção dos sistemas abertos pode ser verificado no concurso para a Berlim Hauptstadt (1957), dos Smithson, proposta esta derivada da Cluster City (1952-1953); na Freie Universität (1963-1979), em Berlim, dos arquitetos Candilis, Josic e Woods; na proposta similar destes mesmos arquitetos para o Römerberg (1963), em Frankfurt; ou para o novo bairro para Toulouse, o Toulouse-le-Mirail (1962-1977), parcialmente executado, no qual há uma mistura de repertórios, tanto dos Clusters quanto das propostas desenvolvidas para as cidades alemãs de Berlim e Frankfurt.

A proposta de Cluster City in the Air (1960-1962), de Arata Isozaki, para o bairro Shinjuku, em Tóquio e a Plug in City (1964) do arquiteto inglês Peter Cook, mesmo sendo teóricas e provocativas, interpretam as unidades ao mesmo tempo independentes e conformadoras do todo. Unidades plugáveis a partir da lógica da montagem-desmontagem, tanto dos sistemas urbano- 
arquitetônicos quanto da própria paisagem. Mesmo que a Tokyo Bay Masterplan (1960) de Kenzo Tange, de mesma base conceitual, tenha impresso uma representatividade aos Metabolistas, tais propostas ficam claras nos projetos de menor proporção de Kisho Kurokawa para a Nagakin Capsule Tower (1972) e para Le Centre Georges Pompidou (1971), que expressam uma espécie de estrutura-matriz responsável por comportar as naturais mudanças programáticas e formais. Essas estruturas espaciais abertas podem ser encontradas no Habitat 67 de Moshe Safdie, no pavilhão das Humanidades2012, das arquitetas Carla Juaçaba e Bia Lessa, e mais recentemente no Plug in City 75 (2017) para Paris, numa intervenção de Stéphane Malka.

\subsubsection{Um olhar para a história}

A história foi também ponto nevrálgico da diluição do purismo. As críticas de Bruno Zevi ao discurso hegemônico da arquitetura moderna já em 1940 indicanos uma forte mudança de curso do MM na Itália. A Continuità, como pressupunham Nathan Rogers e seus discípulos, reinventou o paradigma arquitetônico moderno baseando-se na contaminação histórica, seja a partir da tipo-morfologia urbano-arquitetônica, seja a partir das tradições do construir e do habitar prolongados na história pela cidade. Teatro del Mondo (1979) de Aldo Rossi é, talvez, o edifício paradigmático deste pensamento, mas não o único a revelar as propostas de relação quase mimética do novo com o antigo. As produções de Carlo Aymonino, Giancarlo de Carlo, Vittorio Gregotti, Massimo Scolari, Giorgio Grassi, Enzo Bonfanti, Bruno Reichli, Fabio Reinhardt, Aurelio Galfetti, Livio Vacchini, Oswald Mathias Ungers, Josef Paul Kleihues, José Ignácio Linazasoro, Miguel de Guzmán, Alvaro Siza, Mario Botta e Luigi Snozzi seguem, com alguma afinidade, aos ensinamentos de L'Architettura della cittá de 1966.

Outra vertente que se desdobra a partir da identificação dos híbridos é a corrente pós-moderna norte-americana. Complexity and Contradiction in Architecture (1966) de Robert Venturi e Learning from Las Vegas (1972) de Venturi, Brown e Izenour, aprimoram teoricamente os princípios do simbolismo e se colocam em apologia ao exagero dos híbridos. Robert Venturi, Michael Graves, Philip Johnson, Charles Moore são os nomes expoentes desse pensamento, e a Vanna Venturi House (1962) e Piazza D'Italia (1977) continuam a ser os exemplos paradigmáticos dessa prática.

\subsection{Da cidade ao edifício - a proliferação dos híbridos}

Num segundo momento, a proliferação dos híbridos ocorreu de modo acelerado, seja em autoconstruções ou em projetos de arquitetos renomados (MÁXIMO, 2017). Após os apontamentos de Eisenman, Venturi e Rossi, que colaboraram, cada qual à sua maneira, com a protrusão das esferas purista e funcionalista, Rem Koolhaas identificou na arquitetura moderna de Nova York dois princípios de ruptura do funcionalismo que eram gestados desde 1930 a partir da Lobotomy e do Schism. Desde sua publicação Delirious New York (1978), novas propostas dos híbridos foram pensadas e materializadas, e o curso dessa história se encaminha a partir das seguintes manifestações.

Híbrido de programas - Demarca-se nesta proposta dois deslocamentos: 1) da função aos usos; 2) do edifício multifuncional ao edifício híbrido. Em certa medida, esses deslocamentos se convergem e mutuamente se influenciam. A 
Unité d'Habitation (1952) é um primeiro indício dessa mudança, mas no Silodam Building (1995-2002), em Amsterdã, de autoria do MVRDV, é potencializada a mistura de programas e diversificada amplamente a configuração das unidades habitacionais.

Híbrido de Referências - O Serpentine Pavillion de Sou Fujimoto e a Pixel Cloud Installation de Mayer Architects, ambos de 2013, são sintomas da contaminação direta das propostas dos ingleses e japoneses da década de1960. Não se afasta destes casos a Neossmann (2012), a Pont9 (2014), a Bow-House (2014) ou a 3box (2016) de Stéphane Malka, que propôs próteses arquitetônicas em edifícios e infraestruturas antigas de Paris.

Híbrido de Formas - A unidade arquitetônica, em muitos edifícios híbridos, é mantida. Destaca-se o Silodam como exemplo. Todavia, a mudança de direção de alguns arquitetos sinaliza para tomadas de decisões diversas a depender do caso. O Holland Pavilion (2000) para a Expo 2000, do MVRDV, aponta uma profusão de formas, estruturas, usos e circulações, ainda que condensadas de modo fragmentado em um único volume. Linked Hybrid (2009), de Steven Holl, encerra numa aparente uniformidade uma ampla diversidade de formas e usos, conectados por uma passarela - uma espécie de rua aérea - que permite o trânsito pelos programas acima dispostos.

Híbrido de tempos - A domesticação da natureza humana por meio da vida urbana é ressaltada pela hibridização dos tempos a materializar-se no espaço. Assim, diacronias, sincronias e anacronias urbano-arquitetônicas estão por toda parte, mas ressaltam um impulso inconsciente à domesticidade. A retomada histórica, ainda que indireta, envereda-se ainda no seio do MM. Refutar os tempos, ali, encontrou força mais nos discursos que nas práticas. Todavia, a contaminação explícita dos tempos evidencia-se nas tessituras pósmodernas, entretanto, de modo bastante variegado. Rossi, Venturi e Krier, assim, intentam tal contaminação. Mais recentemente, a intervenção de Rafael Moneo no conjunto da Plaza del Cardenal Belluga ao ampliar o Edifício da Prefeitura (1991-1998), e o Kolumba Museum (2007) de Peter Zumthor proclamam a fusão dos tempos por meio do espaço, hibridizando-os. Mesmo que o Jewish Museum (1999-2001), de Daniel Libeskind, se coloque amplamente diferente dos projetos supracitados, ele nos indica uma prática ampla de promoção de edifícios híbridos.

\section{UMA ANÁLISE CRÍTICA E PROPOSITIVA PARA O CENTRO DE GOIÂNIA}

A fim de pormos à prova as inquietações levantadas acima, utilizamo-nos do espaço histórico do Setor Central de Goiânia, capital de Goiás, para o exercício de projeto. Para tal, utilizamo-nos das etapas a seguir: 1 - leitura histórica e delimitação do lugar; 2 - estabelecimento do problema de projeto; 3 - proposição de estratégias para responder ao problema; 4 - a apropriação do terreno e materialização das estratégias. É importante salientar que, apesar de estabelecidas essas etapas-macro, sua ordem não indica uma sequência linear de projeto, mas de idas e voltas às etapas anteriores. Dito isto, apresenta-se, em síntese, como cada parte foi estabelecida e trabalhada.

\subsection{Acerca do local - breves apontamentos para uma leitura híbrida}

O desenho polimórfico do traçado do Centro de Goiânia traz, desde seu nascimento, um urbanismo híbrido. Seu traçado, com retas e curvas, e com 
tecido homogêneo - inspirado no urbanismo barroco francês - se desterritorializa de sua atmosfera absolutista europeia e é trazido para o Cerrado brasileiro, para a fronteira esvaziada no interior, no formato refinado e atualizado das práticas modernistas. Isso faz do Plano para Goiânia (19321935), de Attilio Correa Lima (DINIZ, 2007; ARRAIS, 2015), um híbrido, uma mistura de referências acumuladas e materializadas para representar um novo momento político e econômico no país (Figura 1).

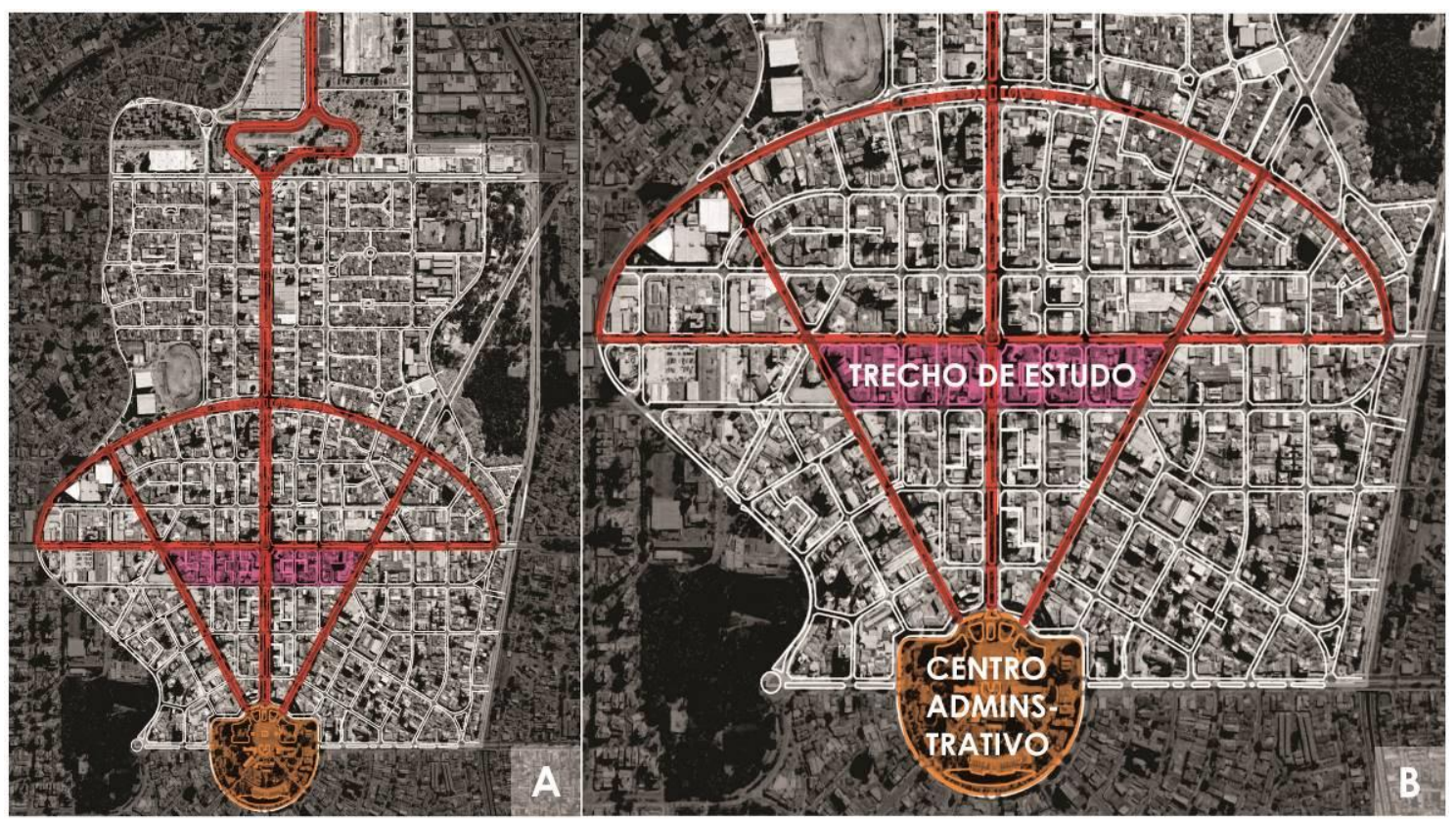

Figura 1 - Macro: Setor Central

Fonte: Imagem satélite Google Earth (2017) / Edição: Larissa Kravchenko

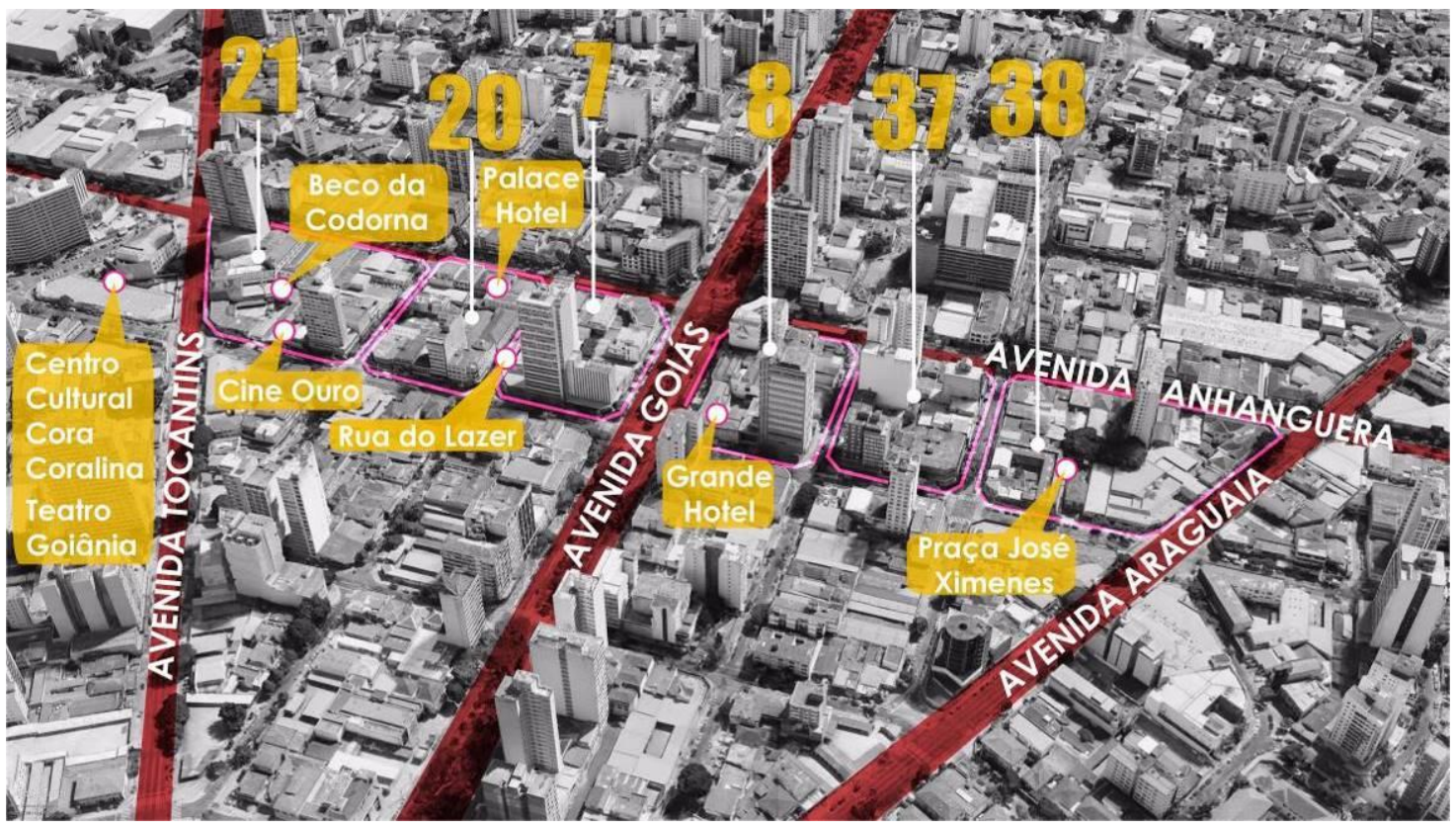

Figura 2 - Trecho de Estudo

Fonte: Imagem satélite Google Earth (2017) / Edição: Larissa Kravchenko 
Na proposta de Attilio mais expressiva, apesar de mudanças, é o traçado viário que ligaria o Centro Administrativo ao Centro Comercial. Atualmente são vias de passagem e ainda desempenham um papel importante na estrutura urbana da cidade. São exatamente entre esses grandes eixos (Avenida Anhanguera, Tocantins, Araguaia e Goiás) que foi delimitado o trecho de estudo (Figura 2).

A quadra escolhida para o desenvolvimento do trabalho foi a quadra 21 localizada entre a rua 9 e rua 3, Avenida Tocantins e Avenida Anhanguera. Nela se abrigam muitos elementos interessantes como o Beco da Codorna que abre a quadra para o pedestre. Ele já foi palco de muitos eventos culturais e atualmente abriga o Museu de Arte Urbana, essa arte colore todas as paredes internas da quadra sendo área de exposições de muitas artes. Também o histórico e popular Cine Ouro (Centro Municipal de Cultura Goiânia Ouro) em uma galeria comercial, ambos são pouco utilizados atualmente, possuindo muitas lojas vazias.

\subsection{O problema de projeto}

Contemporaneamente, o Setor Central desempenha um papel importante na Metrópole, principalmente pelo sistema viário articulador e infraestrutura urbana existente. Porém, quando analisamos sua ocupação e usos é possível perceber que há um considerável número de edifícios abandonados ou subutilizados, em detrimento daqueles em que são explorados seu máximo potencial. Este é o caso da quadra 21 que possui o maior índice dentre o trecho analisado, cerca de $20 \%$ de seus lotes estão subutilizados e grande parte das salas das galerias comerciais da quadra estão desocupadas (Figura $3)$.

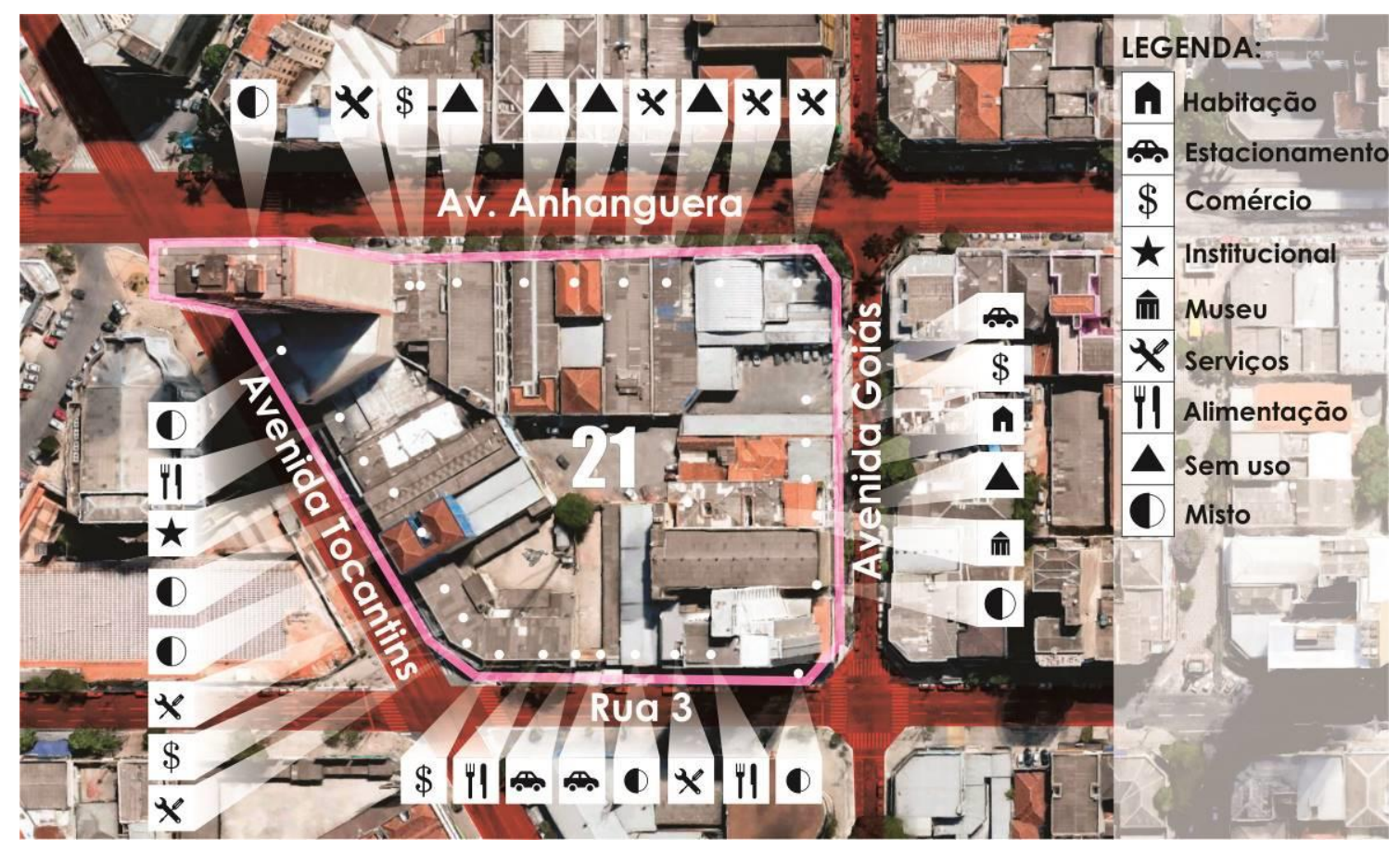

Figura 3 - Uso e ocupação da quadra 21

Fonte: Imagem satélite Google Earth (2017) / Edição: Larissa Kravchenko 
Quanto aos usos, observa-se a predominância de comércios e serviços que atraem fluxos das mais diversas regiões da Metrópole, todavia, majoritariamente em horários comerciais. Isso indica que há uma espécie de subutilização do Setor Central período noturno e aos finais de semana - fato aparentemente comum no Centro das cidades-capitais brasileiras. De acordo com os estudos dos usos e horários de funcionamentos da quadra 21, foi possivel observar a falta de atividades que induzam à vida noturna diversificada, o que a torna ociosa e perigosa nesse período. Quanto à análise perceptiva do lugar percebe-se também a necessidade de um espaço de uso coletivo que seja capaz de condensar e catalisar as práticas culturais e interação dos usuários.

Assim, na Análise do Lugar não foi identificado somente sua subutilização, mas a baixa qualidade do ambiente construído - que se encontra, em alguns pontos, em deterioração ou já deteriorados -, e a falta de uma diversidade de usos que seja suficiente para garantir a presença de usuários nos períodos de esvaziamento. Quanto ao caráter histórico, tem-se os edifícios Cine Ouro e Edifício Anhanguera (onde se localizava o antigo Cine Capri), que mantêm parcialmente os usos iniciais e que ainda atraem usuários. Neste sentido, diferentemente da intervenção na quadra do Teatro Goiânia, localizado na outra face Avenida Tocantins, estipula-se que é preciso ir além da conservação e restauração de bens. A intervenção na quadra lindeira, de uso essencialmente cultural que conta com a Vila Cultural Cora Coralina e com o Teatro, não foi suficiente para provocar uma mudança do padrão de usos, em especial dos usos noturnos. Assim, entende-se que é preciso integrar os bens históricos com a vida da população, atualizando-os.

Por isso é pertinente a implantação de Edifícios Híbridos, já que promovem a proliferação dos híbridos. Esse tipo de construção vai além do arquitetônico, busca-se a melhor relação da construção com a cidade e da construção com o edifício. Sua multifuncionalidade nasce da necessidade do local, assim integra-se novas atividades e espaços de qualidade para o encontro, convívio e permanência de toda a população.

\subsection{As estratégias de projeto}

Na quadra escolhida, foi proposto a demolição das edificações dos lotes 27, $29,3,44,42,38,40$ liberando uma área de $4.370 \mathrm{~m}^{2}$ para o exercício de projeto. Respeitando o desenho original da quadra, o núcleo (Beco da Cordorna) será mantido e será o principal ponto de encontro do desenho proposto (Figura 4).

Na escolha do programa buscou-se equilibrar os usos e horários de modo que a quadra tenha utilização e circulação de pessoas em todos os períodos do dia: integrou-se as atividades de cultura e lazer. Com isso objetivou-se garantir a sociabilidade e as trocas neste trecho do Setor Central. No projeto combinou-se programas em escalas, usos e públicos diferentes. Para estimular a permanência dos usuários na quadra e prolongar os usos, foram integrados ao programa café/pub, bar/restaurante e alguns usos 24 horas. Constatandose o pequeno número de bibliotecas no entorno imediato, agregou-se este uso ao programa e estabeleceu-se a conexão dele com outros usos de cunho cultural. 


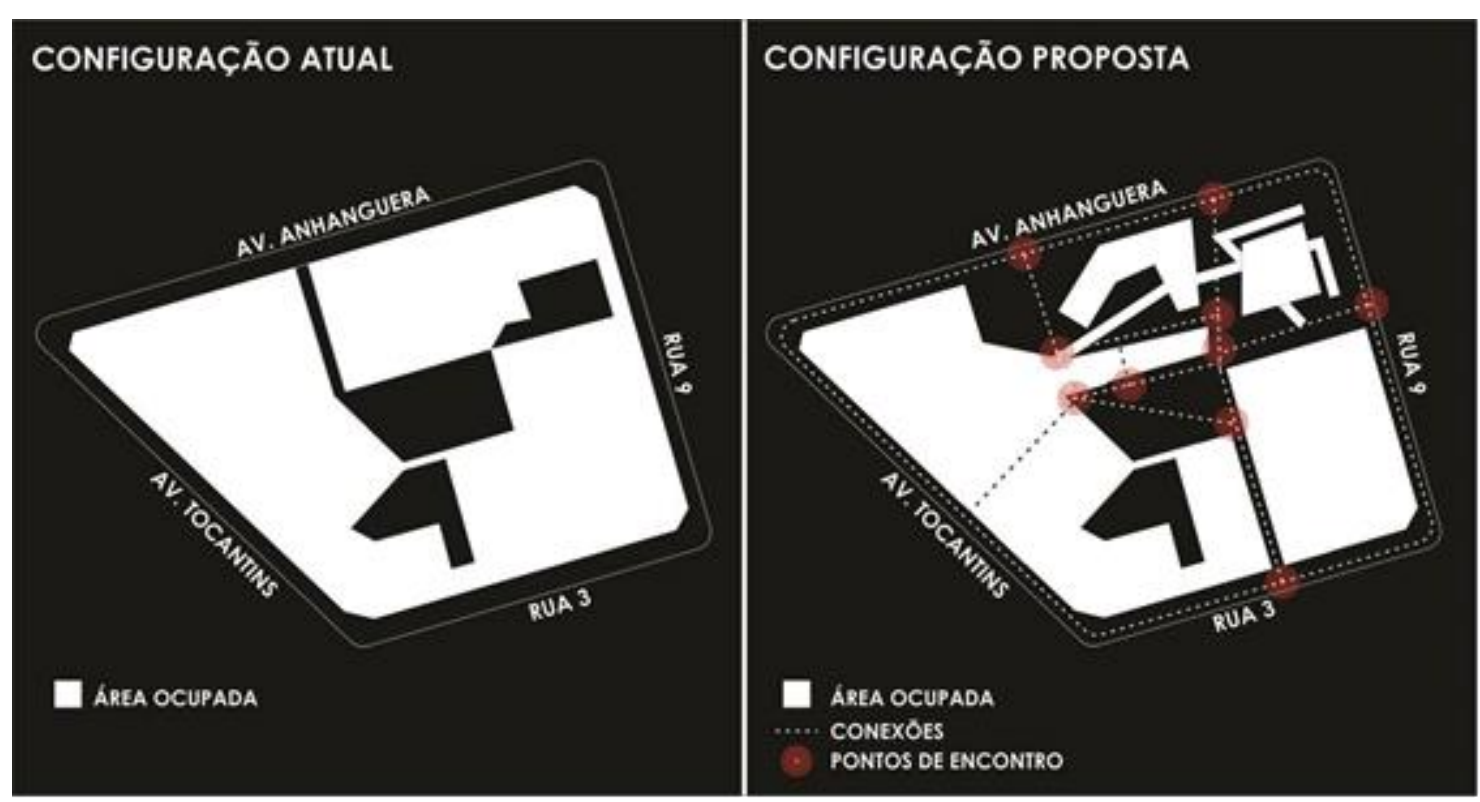

Figura 4 - Diagrama comparativo: Configuração atual e proposta Fonte: Imagem satélite Google Earth (2017) / Autoria: Larissa Kravchenko

\subsection{A apropriação da quadra 21 e a materialização das estratégias}

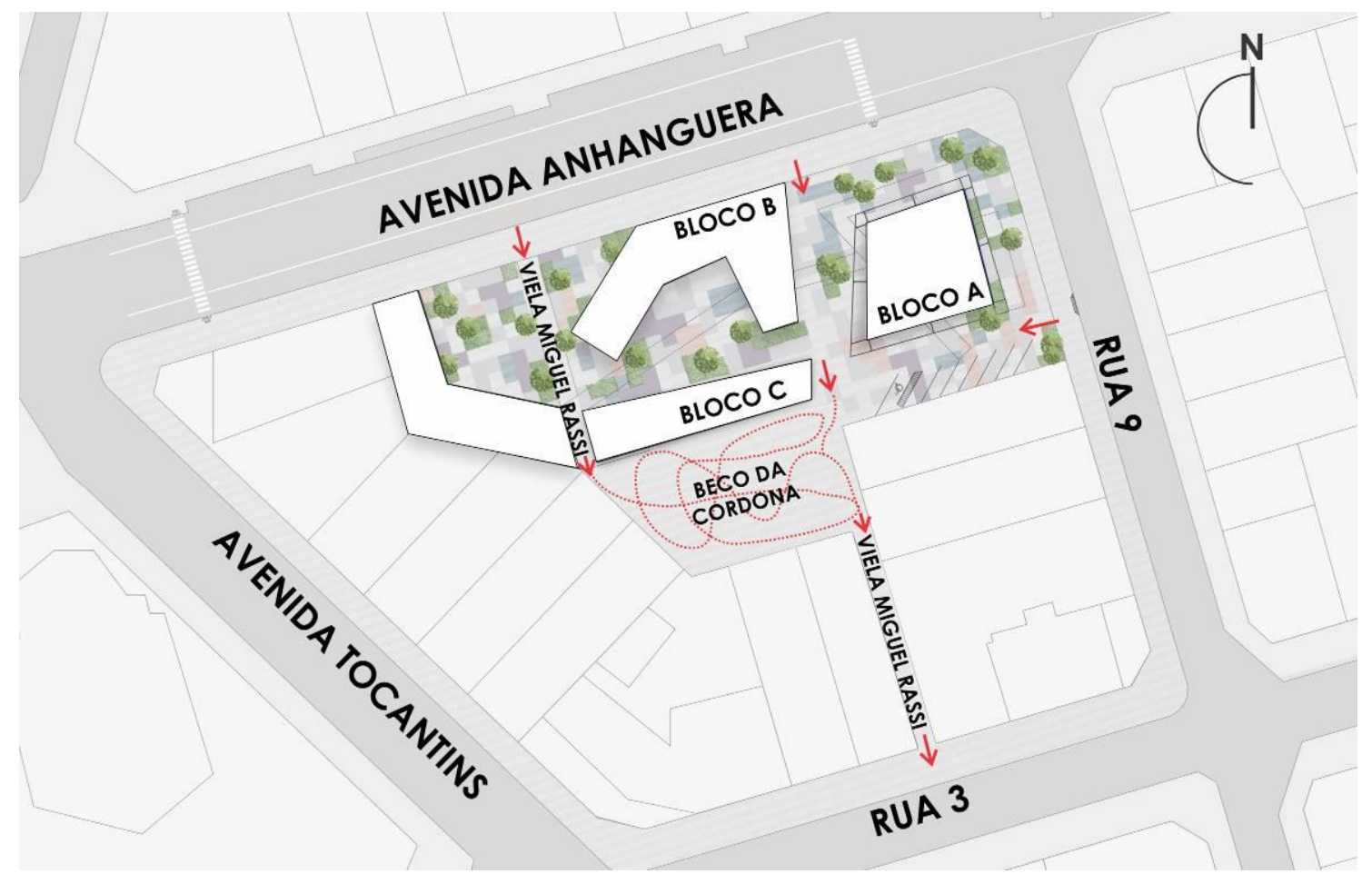

Figura 5 - Implantação

Autoria: Larissa Kravchenko

Os edifícios foram divididos em 3 blocos (Figura 5), cada um com sua identidade, desenho e programa. O Bloco A (Figura 6) foi inspirado em pixels. Ele é fruto da contemporaneidade, da circulação pulsante materializada pelas faixas vermelhas que o atravessam e que ora são passagens, ora encontros, ora contemplação. Mais que todos, aqui os estranhos se encontram, se veem e se cumprimentam. Nele estão divididos os programas da Agência Bancária, Biblioteca e Café/Pub. 


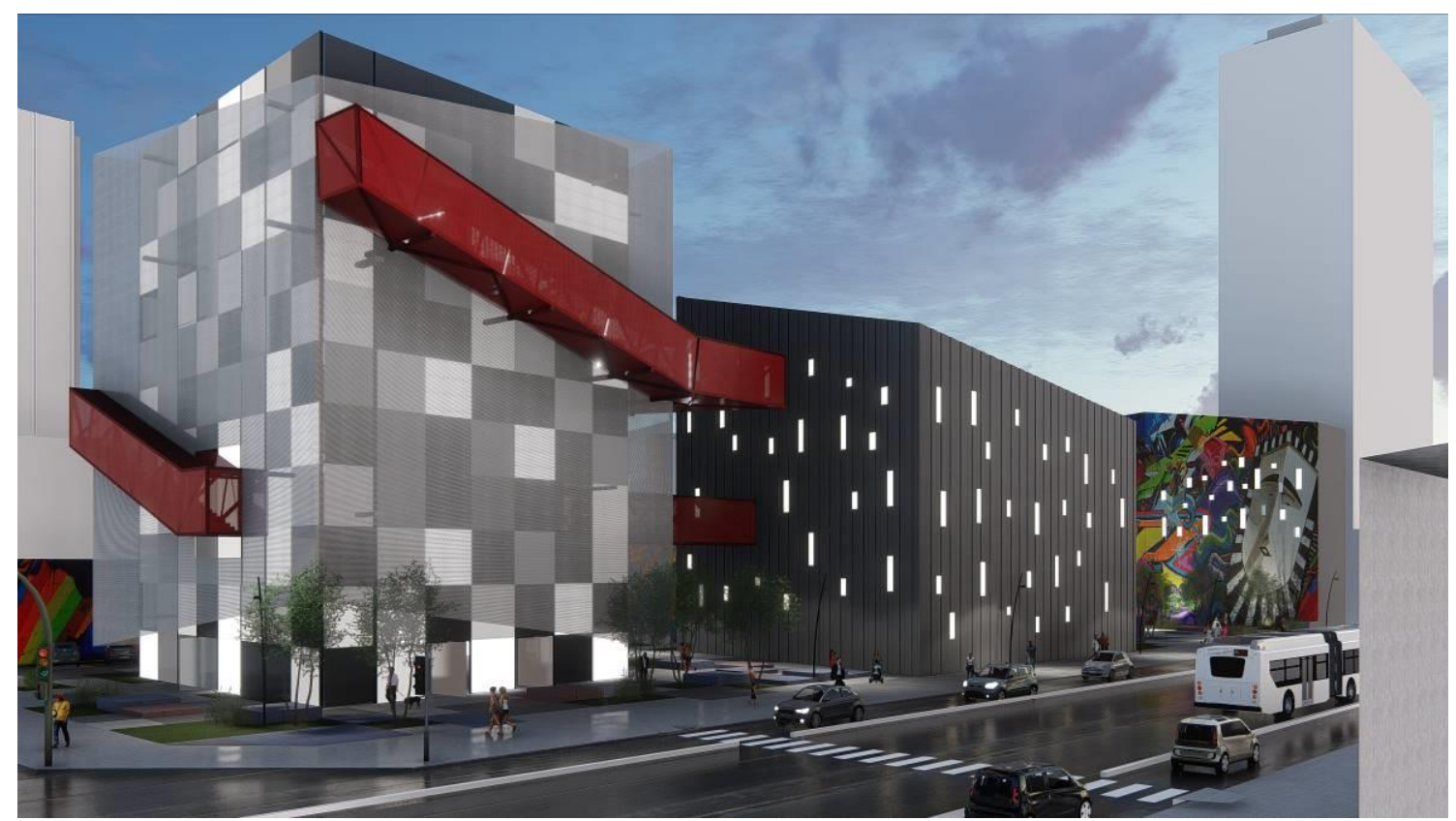

Figura 6 - Vista da Avenida Anhanguera com a Rua 9

Autoria: Larissa Kravchenko

Já o B (Figura 7) é bloco das passagens e encontros, ponto de convergência de pessoas de todos os lugares. É a casa dos híbridos, é para estar, permanecer ou talvez só passar, é para conhecer, comer, beber e encontrar. Ele abriga os programas do Hostel, Bar/Restaurante e Coworking.

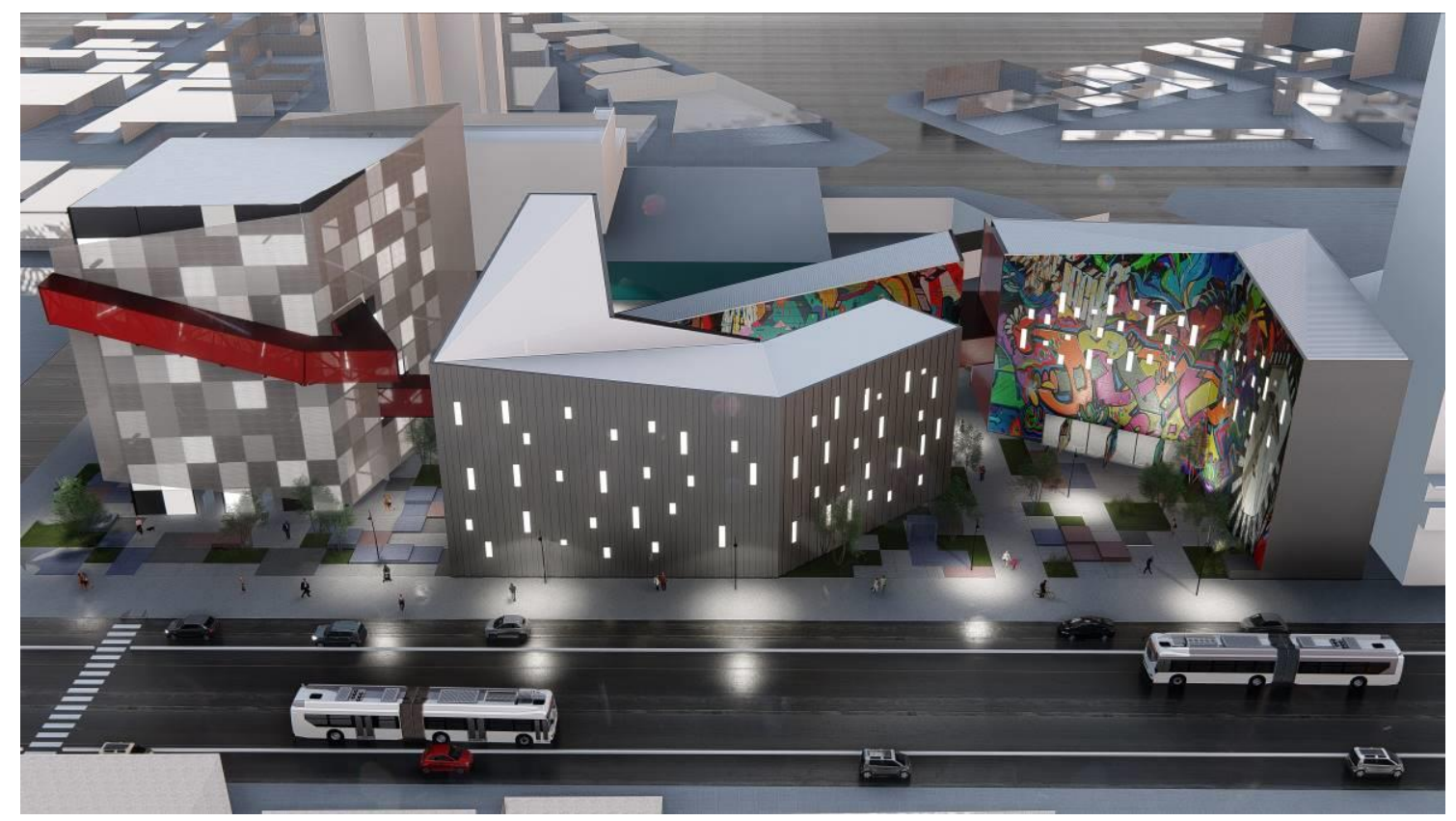

Figura 7 - Vista da Avenida Anhanguera

Autoria: Larissa Kravchenko

A arte urbana é a arte da cidade, é a arte democrática, é a marca das ações humanas, reflexo do momento político, histórico, social e cultural em que a cidade está inserida. O bloco C (Figura 8) é a tela dessa arte, é mutável, inconstante e é das pessoas como a cidade. É nele que se encontram os programas do Museu de Arte Urbana, Escola de Grafite, Auditório, Café e Livraria. 


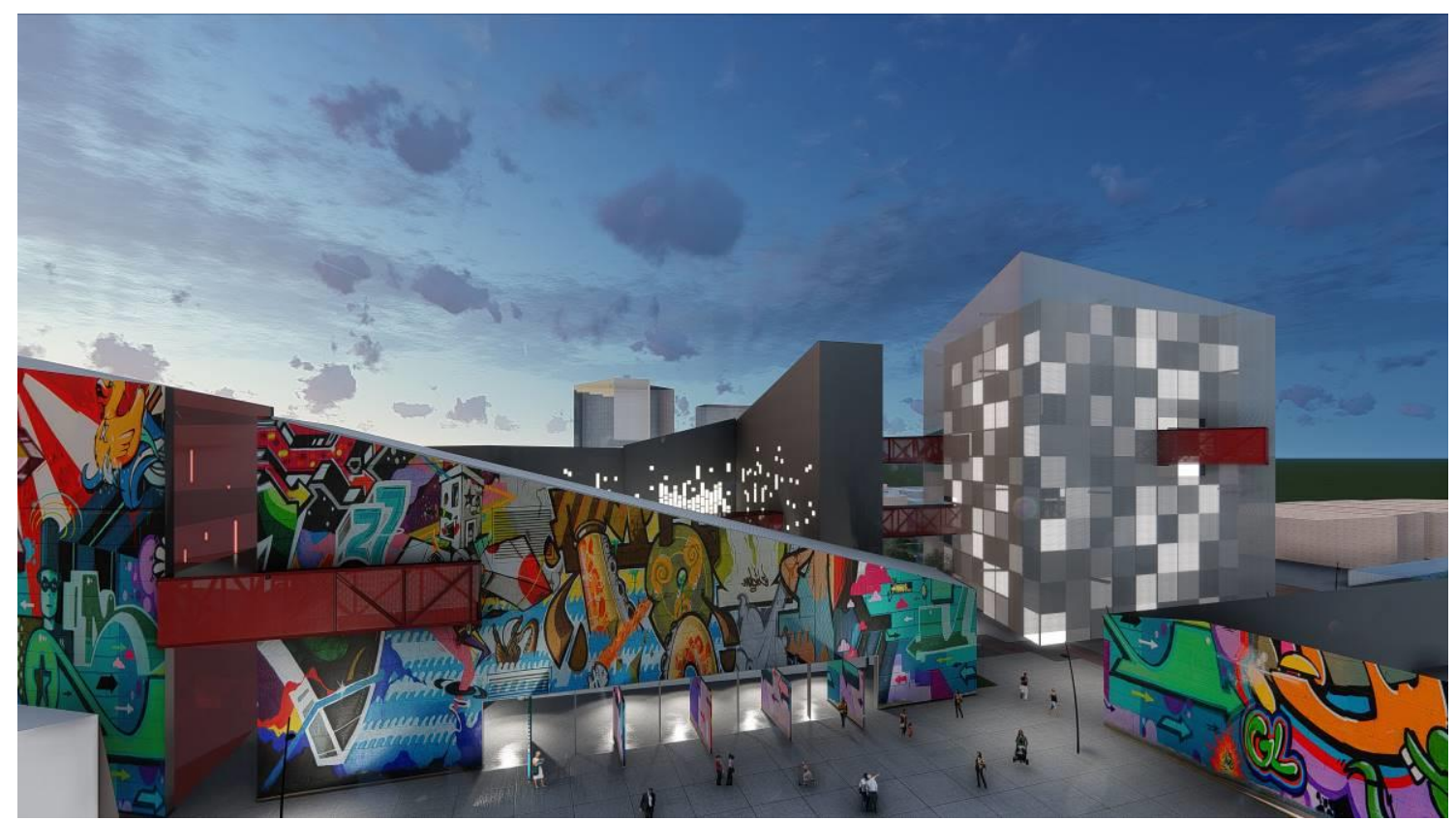

Figura 8 - Vista do Beco da Codorna

Autoria: Larissa Kravchenko

A definição do espaço a ser ocupado pelos edifícios teve com como principal diretriz a circulação. Na busca de criar espaços abertos que convidem o pedestre adentrar e utilizar a quadra as formas abraçam e criam diferentes experiências entre o usuário com a construção. A circulação difusa integra os edifícios ao Beco da Codorna respeitando sua forma, ocupação e a importância histórica, social, cultural e paisagística que ele desempenha.

O partido arquitetônico em blocos se deu a partir de formas primárias que passam por transformações, adições e subtrações até posteriormente chegar à forma final. Unindo-se os blocos e os eixos de conexões (passarelas) têm-se a composição final dos Edifícios Híbridos propostos. O projeto buscou quebrar a monotonia presente, assim, foram criados intervalos entre os blocos. Neles foram propostas áreas de convivência que, por meio da materialidade e do paisagismo, integram o todo, da calçada aos edifícios garantindo sua continuidade. Esse espaço intermediário aberto à multiplicidade de significados e usos servirá tanto aos edifícios quanto à cidade. Buscando uma melhor interação com a paisagem os edifícios propostos respeitam o gabarito de alturas do entorno.

Assim, os pontos norteadores do projeto foram as circulações e os acessos à quadra, a fim de garantir a permeabilidade e possibilitar caminhos por entre os edifícios. A ideia original do traçado de Attilio foi respeitada, mantendo a rua de serviços Miguel Rassi e criando sua continuação da rua de serviços ao lado do Cine Ouro. Deste modo, a hibridação dos edifícios vai além de sua estrutura programática, da circulação difusa, da composição formal e estruturação espacial, ela também está presente sobreposição de materiais e diferentes tecnologias, como por exemplo a estrutura metálica, as lajes em Steel Deck, as alvenarias em concreto celular, os fechamentos em chapa metálica perfurada, vidro insulado laminado e painéis de 3 form que compõe o projeto dos híbridos. 


\section{REFERÊNCIAS}

ARRAIS, Juliana. Os Espaços Públicos em Áreas Centrais: Configuração,

Vitalidade E Infraestrutura ociosa no Centro Antigo de Goiânia. Dissertação (Mestrado em Arquitetura e Urbanismo) - Universidade de Brasília, Brasília, 2015.

DINIZ, Anamaria. Goiânia de Attilio Corrêa Lima (1932-1935): ideal estético e realidade política. Dissertação (Mestrado em Arquitetura e Urbanismo) -

Universidade de Brasília, Brasília, 2007.

JACQUES, Paola Berenstein. Montagem de uma outra herança - urbanismo, memória e alteridade. Tese (Titulação) - Universidade Federal da Bahia,

Salvador, 2018.

MÁXIMO, Pedro Henrique. Por uma cidade híbrida. Mobile (UEG), Anápolis, v. 1, 2017. 